\title{
Socioeconomic Status and Individual Personal Responsibility Beliefs Towards Food Access
}

\author{
Robert A. Coleman ${ }^{1}$ (D) Mark D. Fulford ${ }^{2}$ (D)
}

Accepted: 6 October 2021 / Published online: 25 October 2021

(c) The Author(s), under exclusive licence to Springer Nature Switzerland AG 2021

\begin{abstract}
Despite worldwide attention given to food access, very little progress has been made under the current model. Recognizing that individual engagement is likely based on individual experiences and perceptions, this research study investigated whether or not a correlation exists between one's socioeconomic status (SES) and perceived personal responsibility for food access. Discussion of results and implications provide fresh insight into the ongoing global debate surrounding food access. Outcomes also provide insight into willing and able participants and point to least-cost solutions which may be better suited to implement and initiate change. Results indicate that the issue of food access is more complex than simply lobbying for better decision-making among individuals and populations, highlighting the importance of unit of analysis considerations.
\end{abstract}

Keywords Food access $\cdot$ Perceived responsibility $\cdot$ Socioeconomic status $\cdot$ Learned helplessness $\cdot$ Least-cost

As attention to global food access and food related issues increases, many studies have been conducted offering potential solutions to the global health issue related to non-communicable diseases (NCDs), human rights, food justice, and food sovereignty. As a result, opinions on potential food access solutions are abundant with many calling on privatepublic partnerships in addition to a call for corporations to do more under the guise of corporate social responsibility (CSR). Yet, in 2014, the United Nations concluded that very little progress had been made under the current models. The authors believe there is shared responsibility that can benefit from partnerships, but responsibility resulting in positive change likely cannot be addressed through large scale solutions or one size fits all approaches that overlook the issue at the unit of analysis, or individual, level.

Our approach to responsibility surrounding food access as hypothesized in this study, which recognizes that the global issue comprises the individual, offers that responsibility will fall on different actors in differing degrees dependent upon traditionally measured

Robert A. Coleman

robert.coleman@findlay.edu

1 College of Business, University of Findlay, 1000 N. Main St, Findlay, OH 45840, USA

2 School of Business, Economics, and Technology, Campbellsville University, 1 University Drive, Campbellsville, KY 42718, USA 
socioeconomic factors. Further, considering that it is the individual who ultimately must engage with change to impact outcomes, we offer that how an individual perceives their personal responsibility for a change issue will be related to one's SES. With this understanding, the question that guides our inquiry asks if individuals of differing SES perceive personal responsibility for food access differently? Findings indicate that individuals across varying SES levels do view their responsibility for food access differently and provide empirical support to barriers surrounding implementation of ideas and programs intended to improve access. In other words, the study findings speak to why the current paradigm has been ineffective and highlight the need to rethink current efforts.

Currently, much of the research in food and beverage related fields focuses on the nutritional aspect of products (Cornil et al. 2020; Stuckler and Nestle 2012; Tempels et al. 2017; Botterill 2017; Gostin 2016) with access playing a role in consumption and subsequent nutritional outcomes affecting the health of the individual. Current research, therefore, is focused on global health as, in the U.S., there is an increase in obesity and associated health issues (Chen and Wang 2021; Persoskie et al. 2017) and health costs are increasing in part due to decisions surrounding food consumption. However, human food choice behavior is not as clear cut as choosing a food one likes when hungry (Scott 2017); in fact, for some, food choice is not an option. As a result, targeted solutions to these issues must understand the role participants play in the food industry - more specifically, the roles and responsibilities individual actors see themselves filling.

Ongoing discussion surrounding responsibility related to access and health appears to assume that all actors are at the table, ready and willing to participate in positive change as soon as a conclusion is reached as to who the responsible party is for food and food-related decisions. It is no surprise that, according to the United Nations (UN), very little progress has been made under the current partnership model (Marks 2017) pursued in an effort to foster positive change, yet the trend continues. At the moment, there does not appear to be a clear-cut solution or agreement as to the nature of participant responsibilities on a global scale. In addition, much of the existing literature appears to reflect this situation from a qualitative standpoint and the global community cannot agree on a starting point in pursuit of improved outcomes.

\section{Food Access: An Ongoing and Increasing Issue}

Many individuals today (due to factors such as lack of: time; food education; access; or economic resources) are contributing to their current or future poor health through the consumption of foods readily available which introduce unnatural chemicals into the body. The actions ultimately undertaken by individuals regarding food consumption feeds into information listed by the World Health Organization (WHO) in June 2021 regarding 2016 estimates that show approximately 1.9 billion adults and forty-one million children under five years old were overweight or obese; numbers which were greater than the level of the undernourished population (Browning 2017). In addition, the Food and Agricultural Organization (FAO) of the UN reported a global one-year increase of approximately 1.5 percent in the prevalence of undernourishment between 2019 and 2020. The increase brought greater challenges to achieving the goal of Zero Hunger by 2030 (FAO et al. 2021); a goal that was already in jeopardy prior to the COVID-19 pandemic (HLPE 2021). It is now estimated, using median values of range estimates published by the FAO, that 2020 found 118 million more people facing hunger than in the previous year (FAO et al. 
2021). Therefore, we see that in addition to worrying about hunger, the concern has also become obesity as well as diabetes and heart disease; non-communicable diseases (NCDs).

Historical research on food responsibility offers differing opinions as to where responsibility lies when it comes to NCDs. Corporations point to other actors such as the individual whereas the individual points back to the corporation (Mialon et al. 2016a) while government and non-governmental organizations (NGOs) are also said to play a role. Much of the current research speaks to the idea of partnerships and shared responsibilities between public and private entities (Marks 2017; Tempels et al. 2017; Calveras and Ganuza 2016), while at the same time, other research refers to corruption present among partnerships and lobbying in the development of policy (Wiist et al. 2017; Mialon et al., 2016b) that can impact outcomes. Regardless, there does not appear to be a shift in the global leadership mindset regarding the issue as those with positional power in the global discussion continue down the familiar path.

For example, the 2021 United Nations Food Systems Summit (UNFSS) (developed as a partnership between the World Economic Forum and the UN) continues with the current global paradigm and has been criticized for failing to avoid conflicts of interests in the form of corporate financial and non-financial pursuits. In addition, they have been accused of undermining "more democratic arenas of global food governance, while reinforcing corporate control over food systems" (p. 2). In fact, the UNFSS 2021 is said to have further allowed corporations the ability to affect decision-making and outcomes (Canfield et al. 2021) in the presence of serious concerns from Intergovernmental Science-Policy Platform on Biodiversity and Ecosystem Services (IPBES), Indigenous Peoples, grassroots movements, and social movements to name a few as well as those from other civil society organizations (CSOs) ("Civil Society" 2021). This continuation of the existing model, which reinforces corporate control, is further understood as a pathway that continues to threaten small-scale agriculture in favor of industrial agriculture, negatively affecting food security and production in many areas (Chan et al. 2019).

Thus, the continued adherence to current trajectories by many, such as that by UNFSS, as well as the disconnected focus and discussion surrounding responsible parties which fractures collaborative efforts, does not support necessary global progress. Human health and nutrition will continue to be topics at the forefront of public debate and discussion as people continue to call attention to food systems that may negatively impact them (Jones and Ejeta 2016). In addition, the impact consumed foods have on the individual is likely to become more important as populations increase, global diets change, food choice remains a barrier, access remains an issue, and an individual's time allotted for healthier, slower cooking foods, decreases. As globalization continues, increased focus will be placed on NCDs, food access, food education, consumption, lifestyle, hunger, and purchasing habits to name only a few. With the increase in globalization, concern for social and environmental issues continues to grow and this is true for areas such as the food industry that have an impact on human health (Chen et al. 2016). As such, human rights, food sovereignty, and food justice are areas of increased research and awareness and there is a call moving forward for more study in these fields as many are impacted by the way food is currently produced and distributed. Those at the margins of society are demonstrated to be impacted the most and neoliberalism is shown to offer challenges to feeding those who also find themselves in the expanding urban environment without sufficient resources (Clendenning et al. 2016). As a result, even a decade ago Wittman (2011) referenced the fact that food movements that sought greater access and rights to food were growing.

As with the majority of research in this area, it is relatively young in the context of social science study. Growing food movements, which identify food access as a human 
right, are an ongoing field of research with much opportunity to focus on more nuanced approaches and bypass blanket solutions. The last several decades have been instrumental in this area as researchers have dedicated much effort to identifying areas of concern and trends in social movements. However, the gap that appears to exist is to now take the discussion from one of moral platitudes and grand scales, and approach future studies from the bottom-up on a more personal level gaining the perspective of those impacted with a unit of analysis approach.

\section{Food Access Identified}

Food access as a human right was identified decades ago in the International Covenant on Economic, Social and Cultural Rights (ICESCR), a multilateral treaty, as a "fundamental right of everyone to be free from hunger" ("United Nations General Assembly, International" 1966, Article 11). While attracting much attention, expansion, and agreement since, the Committee on Economic, Social, and Cultural Rights (CESCR) recognized three decades later that hunger and malnutrition still exist in both developed and developing countries; something they attribute to "not lack of food but lack of access to available food" ("United Nations Economic" 1999, p. 3, emphasis in original). ICESCR further linked access to food with its availability, which refers to food being available "in a quantity and quality sufficient to satisfy the dietary needs of individuals, free from adverse substances" ("United Nations Economic" 1999, p. 3). Furthermore, the discussion related to access also included "both economic and physical accessibility" ("United Nations Economic" 1999, p. $3)$.

Individuals with inadequate access to markets to purchase healthy foods, due to economic and physical constraints, are then at greater risk for experiencing undernutrition, lower birth weights, and NCDs as they consume "processed foods that are often energydense, high in saturated fats, sugars and salt, and low in fibre" (FAO et al. 2021, p. 27). Considering the constraints, the issue is further exacerbated as Popkin et al. (2012) shared that energy-dense foods that are low in micronutrients also combine with being more readily available at relatively lower price points.

In an effort to further the definition of access, Usher (2015) conceptualized five dimensions in recognition of objective criteria as well as perceived elements; acceptability, accessibility, accommodation, affordability, and availability. The conceptualization is identified as a mix of factors related to the acquisition of, as well the potential benefits from, healthy food. (Usher 2015). In addition, language utilized in the 2030 Agenda for Sustainable Development adopted by the United Nations General Assembly on September 25, 2015 includes the desire to provide access to "safe, nutritious and sufficient food all year round" ("United Nations General Assembly, Transforming" 2015, p. 35, target 2.1); a sentiment later reiterated in the document to read, "sufficient, safe, affordable and nutritious" (United Nations General Assembly, Transforming, 2015, p. 4). Therefore, review of the discussion surrounding food access reveals that a definition of food access cannot be disconnected from considering subsequent and potential health impacts and must consider nutrition as part of access evaluation.

Following a review of existing definitions and discussion surrounding various considerations of food access, this research (in line with the 2030 Agenda for Sustainable Development adopted by the United Nations General Assembly in 2015) herein defines food access as the economic and physical accessibility to sufficient, safe, affordable and nutritious food 
all year round. Of note, and consistent with this research into perceived responsibility for food access, is that the importance and context of the community as well as its role in food access will differ across individuals, cultures, and locations and must consider the viewpoint of the participant. This is an important distinction as the definition in this study includes consideration and recognition of more personal solutions and discussion surrounding food access (such as the impact of individuals' differing economic conditions); not broad-brush solutions to a highly individualized issue. Further clarifying, while this definition at its foundation pulls from established global discussion, it is important to note that here it is thought to be applicable on a more personal level. Therefore, this definition lends itself to the goals of this study where self-reported information, to include perceived responsibility for food access, will be analyzed in relation to SES.

There are several food theory approaches studied today that include citizen-consumer, food security, food justice, food sovereignty, and food democracy. Among these food theories, food access is included as a basic human right while operating under the idea of the consumer as an active participant in that right. For example, as a citizen-consumer (a theory that emerged from the political consumerism of the late 1980s), one was viewed as being able to influence the collective market through purchasing decisions and choice. Food access is a common theme throughout these theories as food democracy further calls for individuals to get involved and to be active participants in the process (Lozano-Cabedo and Gómez-Benito 2017). The theories listed point to input and production outcomes from a system where the consumer, in addition to other actors, play active roles in the process.

However, with a current reliance on active participants, we are driven in this study to inquire about those citizens who no longer view themselves capable of influencing outcomes in their surroundings. Identifying that someone has the right to something, access to food in this case, does not conclude that they are willing or able to embrace that right. Therefore, it is thought that there are those in society who will not benefit from any collective theory, even if for their own good, and that socioeconomic status (SES) [traditionally comprised of three of the most common indicators such as income, occupation, and education (Psaki et. al. 2014; Niu 2017; Darin-Mattsson et al. 2017)] will correlate with how individual actors perceive their responsibilities for food access.

\section{Independent and Dependent Variables}

The study presented in this paper looks to show that the starting point need not be a single large-scale solution, but rather a varied and more nuanced approach with the idea of taking the first step. To accomplish the objective of this research project, we attempted to identify how members of differing SES classifications perceive responsibility for nutritional food access-which ultimately affects health. The idea is that once this relationship is recognized, it will refocus effort to generate small scale successes that will breed continued momentum and ultimately involve other actors found in the large-scale debates.

A pilot study was conducted to identify any concerns or issues with the data collection method and to highlight modifications that may be required in the instrument used to measure the study variables before final study implementation. With many studies depicting a decrease in survey participation in recent decades, potentially leading to nonresponse bias (Guo et al. 2016), and as cultural behavior can affect response styles, it is important to understand response trends to properly interpret and collect sufficient data as response tendencies are no longer defined by a clear boundary (Kemmelmeier 2016). Thus, conducting a pilot study allowed the researchers to incorporate any necessary changes into the final 
study to promote sufficient and relevant data collection necessary to answer the research question.

\section{SES as Independent Variable}

Our contribution offers that in the current change efforts there is a lack of attention given to the situation from a micro level and that top-down approaches overshadow those that could be viewed as bottom up. Concerning the individual, which we consider to be a bottom-up approach, a study by Li and Chen (2018) demonstrated that how one views their socioeconomic status can influence the choices and decisions they make. Another study found that those in lower SES households needed additional policies in place in order to be on a level playing field with other SES groups when it comes to food choice as economics was shown to be a "rate-limiting factor in the process of food decision-making" (Daivadanam et al. 2015, p. 6). In addition, a case study utilizing McDonald's in Australia demonstrated that the franchise was more likely to be found among geographic locations associated with lower SES (Anaf et al. 2017). These studies show that SES can be an indication of limited choice and alter decisions made by individuals, with economics being a key indicator from a socioeconomic standpoint. Therefore, we think it a key pursuit to ask how those of differing SES perceive their personal responsibility for food access; a bottom-up approach as opposed to top down.

Socioeconomic status is thus used in this study as the independent variable (IV) as it is a theoretical construct affecting access to resources (Psaki et al. 2014) and is thought to be correlated to how one perceives their role in the decision-making processes associated with food access. Traditionally, SES has included three components of measurement; income, education, and occupation (Daivadanam et al. 2015; Niu 2017; Wang et al. 2018). However, this study focuses on income as a proxy for SES as income has been discussed as a key indicator surrounding food related decisions [income and food insecurity are positively correlated (Holt-Giménez and Patel 2009)] as lower income households are unable to access more expensive food. In addition, it was also important to gather information on the number of persons in the household to facilitate converting reported household incomes to a uniform household size using equivalence scales. The use of equivalent scales for this purpose is favored by researchers (Ebert and Moyes 2003) where this scale, used for tractability, is dependent upon the number of people in the household (Garner et al. 2003).

\section{Perceived Responsibility as Dependent Variable}

As the dependent variable (DV) in the study, perceived responsibility for food access relates to how individuals view themselves in the process of accessing nutritional foods. This unique consideration adds to the global discussion of food access and the surrounding NCD concerns as, to date, solutions focus on applied ideas that have failed to make a significant impact. As a result, there is the need to understand how an individual sees themselves in this process of nutritional food access instead of others assuming and projecting action items globally without understanding the individuals involved. The conceptual basis offered for this discussion is the social psychological phenomenon of learned helplessness, discussed below.

When discussing patterns of decision-making processes by individuals or groups that appear to not make sense from an onlooker's perspective, choices (or lack thereof) of individuals can foster an idea of apathy or laziness from onlookers. For example, one may 
view their personal ability to access quality or healthier foods as the responsibility of others, thus affecting the choices and decisions they make in the process and disconnecting themselves from the idea of action and consequence. While this may appear to many as an excuse, we offer that the psychological phenomenon called learned helplessness (LH), which has developed as a socially relevant construct, must be considered in the discussion as a potential explanation. The idea of LH has been applied and extended across various social issues as it includes various emotional, behavioral, and biological aspects (Sorrenti et al. 2015) and proves to be a foundation for perceived responsibility as it relates to this study with its inclusion of interpersonal factors.

Much research has been conducted based on the learned helplessness theory in both animals and humans since its development. The theory states that exposure to "uncontrollable aversive stimuli" (Reznik et al. 2017, p. 905) can lead one to perceive situations to be out of their control; such as when a market fails the consumer (Leary and Ridinger 2020). Under this theory, one disconnects their response from events and views each as being independent from one another, affecting goal-oriented behavior and motivation. Here, one no longer searches to be proactive in changing their situation (Reznik et al. 2017) and instead displays passivity in the wake of uncontrollable adverse events.

The learned helplessness hypothesis labeled by the initial researchers stated that organisms that disconnect outcomes from their responses will thus learn helplessness relating to results (Barber 1986). In a 2016 study performed with flies, researchers found that once they removed them from the environment where they developed a feeling of helplessness, the learned helplessness they had acquired dissipated and the attribute was no longer observed (Batsching, Wolf, and Heisenberg 2016). In humans, where learned helplessness has traditionally focused on helplessness as a result of trauma in addition to studies conducted pertaining to academic success, depression, and anxiety, much of the focus has been on stress as an antecedent to depression under the model (Havranek et al. 2016). Understanding perceived responsibility by an individual appears, therefore, to be related in part to the ideas presented in the learned helplessness theory where an individual's experiences can lead to a loss in confidence where they ultimately disconnect outcomes from actions. With this, there is a tendency to stop trying and negative perceived feedback or experiences under the learned helplessness paradigm has an impact on an individual's future performance or engagement. Learned helplessness, therefore, can include the deflection of responsibility to external factors rather than personal effort; this is in keeping with Fincham et al's definition developed in 1989 and speaks directly to the issue of assuming all participants are willing and able to participate and the failure to recognize behaviors cultivated and rooted in previous experiences. Again, it is not as simple as making better choices.

Those individuals who fall into the LH mindset are often frustrated to the point that they feel overwhelmed by a situation. Studies on LH have shown that those who have developed this mindset will avoid challenges and when faced with obstacles, perform at a lower level when acting. Low confidence, motivation, and passivity result (Sorrenti et al. 2015) and this mindset is offered in this study as one of the reasons why the suggestions of creating networks, even within communities (Blay-Palmer et al. 2016) struggle to affect change. It is possible that those within a community who have had similar negative experiences in life, have a greater potential to disconnect action and outcomes and will exhibit traits of learned helplessness. As such, LH as a conceptual framework not directly tested in this paper serves as one of the theories behind this study by suggesting that socioeconomic status (SES) will play a role in the LH of individuals across different levels and will be exhibited by an individual's perceived responsibility. 


\section{Data and Methods}

The instrument used as the foundation for the collection of self-reported perceived personal responsibility is the twenty-six question Responsibility Attitude Scale (RAS) developed by Salkovskis et al. (2000). This questionnaire is often utilized in studies surrounding obsessive compulsive disorder (OCD) (Manoussaki 2015; Kobori et al. 2017; Barrett et al. 2016) and was designed to understand general attitudes and beliefs regarding responsibility. The RAS questionnaire has an original Cronbach's alpha of 0.92 in addition to good test-retest reliability (Ashbaugh et al. 2006) where $r=0.94, \mathrm{p}<0.0001$ (Salkovskis et al. 2000).

Drawing from the original RAS instrument, questions were modified for the purpose of this study. Where questions in the original instrument were found to be more concerned with OCD-specific outcomes (such as harm), they were removed. Other more general responsibility questions that remained (nine items) were modified and adjusted to relate to the present research study surrounding responsibility for food access. While efforts in modifying the RAS were made to retain the original intent of the questions, statistical analysis in the form of Cronbach's alpha was performed following data collection on received responses to ensure the reliability of items in the modified scale. Cronbach's alpha for the modified RAS was 0.80 , indicating internal consistency.

As part of a pilot study, a total of thirty questionnaires, cover letters, and return envelopes were folded and mailed to addresses within the city of Danville, KY to collect primary data. Addresses were randomly selected to participate from a database obtained at the County Courthouse which contained all residential addresses within the city. Danville, $\mathrm{KY}$ was selected as it is an area that has affluent neighborhoods as well as Sect. 8 housing indicating a wide range of household incomes in the area - an important determinant of SES. The randomly selected addresses were then removed from potential selection for the final study so that the same household was not selected twice, thus duplicating participants. The pilot study asked participants to return the completed questionnaire within three days of receipt, informed them that participation was voluntary, defined food access, and highlighted the anonymous nature of the study.

Results from the pilot study were interesting and informative, resulting in changes to the final study. One of the main goals of the pilot study was to indicate potential response rates of participants, which would then be used to adjust number mailed out in the final study. This was done to ensure enough responses necessary to result in adequate statistical power. The pilot study yielded a 13.3 percent return rate.

A statistical power analysis determined that at least twenty-six completed, usable surveys were required for the final study. With minor adjustments to the mailing procedure (using full-sized envelopes to avoid folding the survey instruments, paring down the cover letter that accompanied the survey instruments, and providing an operational definition of food access on the survey instrument), we believed an expected overall 15 percent return rate in the final study to be reasonable. Needing twenty-six usable responses under the conditions of an expected 15 percent return rate meant that 180 surveys should be mailed. However, taking into account the percentage of respondents in the pilot study that indicated their occupation as retired, 320 surveys were sent out in the final study as using SES as IV with income as proxy meant not including responses from retirees as current income may not be accurately reflective of SES.

With the sample frame identified as residential housing units within the city of Danville, $\mathrm{KY}$ and the database scrubbed for non-applicable participants [businesses, out of area mailing addresses, and duplicates], the sample selection process became the focus. Simple 
random sampling via a random number generator from Urbaniak and Plous (2013) was employed to determine the households asked to participate in the study. Each address had an equal chance of being selected. It should also be noted that the researchers requested, prior to receipt of the housing unit database within the city, that all columns containing names of occupants be removed. This was done to help maintain anonymity of the participants.

\section{Final Study}

Of the 320 questionnaires sent out for the final research study, fourteen were undeliverable and returned to sender as the homes were vacant. Out of the 306 remaining, seventysix questionnaires (24.8 percent) were returned for consideration in the study, a significant increase from the pilot study response rate of 13.3 percent-an indication that the adjustments made following the pilot study had a positive impact on response rate. Data for the seventy-six respondents was entered into an SPSS v26 database and responses corresponding to negatively worded items on the instrument were reverse coded. By reverse coding these questions, the items were consistent in their measurement reflection of perceived responsibility as a higher value on the Likert scale indicated more responsibility perceived by the individual.

Filters were then applied for missing data within the scale, the number of persons in the household, as well as income as these are the primary considerations in this study; these filters removed twelve cases resulting in a total of sixty-four. It should be noted that only one case had missing value items within the scale questions and that respondent also did not include the number of persons in the household or income. This is noted as removing cases solely based upon missing scale data could potentially result in removing a case based on missing data in a particular question, where the question itself may not ultimately be used in the analysis or included in the total calculated responsibility score following inter-item correlational analysis. This concern is not an issue here as all missing data cases removed did not include income information.

An additional filter was then included in relation to the occupation response to remove retirees and other occupational non-responses from the analysis. Following this filter application, thirty-four additional cases were removed due to indicating retired as their occupation and two respondents were removed as they did not list an occupation at all. Thus, the database was left with twenty-eight cases. Data cleaning performed to this point was focused on identifying data that was useful in answering the research question, thus removing data non-response cases and retirees. The following steps, performed prior to final data analysis, focused on the quality of the data remaining by testing the assumptions of the Pearson's product-moment correlation coefficient to determine analysis applicability.

\section{Assumptions and Analysis - Pearson's Product-Moment Correlation}

Assumptions of the Pearson's product-moment correlation statistical test necessary in order to produce a valid result when applying the bivariate correlation analysis: Continuous scale; Linearity; Outliers; Normality; Related pairs; and Homoscedasticity. All assumptions of a Pearson's correlational analysis were tested and confirmed for both the IV (SES) and the DV (perceived total responsibility) and the outlier analysis resulted in the removal 
Table 1 Descriptive Statistics for Final Dataset

\begin{tabular}{llllr}
\hline & $\mathrm{N}=26$ & & \\
\cline { 2 - 5 } & Minimum & Maximum & Mean & Standard Deviation \\
\hline Adjusted Household Income & $\$ 5,367$ & $\$ 72,169$ & $\$ 42,112.80$ & $\$ 18,269.04$ \\
Responsibility Score & 9 & 25 & 18.62 & 4.109 \\
\hline
\end{tabular}

Note: Descriptive statistics for final dataset.

Table 2 Final Inter-Item Correlation Matrix

\begin{tabular}{llllll}
\hline & Influence_Q1R & Impact_Q3 & Actions_Q4R & Access_Q5 & Control_Q7R \\
\hline Influence_Q1R & 1 & 0.647 & 0.35 & 0.357 & 0.716 \\
Impact_Q3 & 0.647 & 1 & 0.464 & 0.213 & 0.635 \\
Actions_Q4R & 0.35 & 0.464 & 1 & 0.042 & 0.57 \\
Access_Q5 & 0.357 & 0.213 & 0.042 & 1 & 0.253 \\
Control_Q7R & 0.716 & 0.635 & 0.57 & 0.253 & 1 \\
\hline
\end{tabular}

Source: Author's calculations ${ }^{\mathrm{a}}$.

Notes: Indicates the final inter-item correlation matrix following the removal of Q2, Q6, and Q8.

a) Final Cronbach's $\alpha=0.80$.

of two cases, for a total of twenty-six cases remaining. Table 1 shows the descriptive statistics for the final data set.

Additionally, an examination of the original inter-item correlation matrix of the items in the perceived responsibility scale showed three items to be weakly related to the others and they were removed from the scale, resulting in a total of five items comprising the modified RAS. Table 2 shows the inter-item correlation matrix results after removing the scale items indicated followed by a between variables analysis addressing the research question through Pearson's $r$.

With the final data set prepared, the Pearson correlation statistical test was performed to determine if a statistically significant relationship exists between SES and personal perceived responsibility for food access. The Pearson correlation was used to test the null hypothesis that there is no statistically significant difference in how individuals perceive personal responsibility for food access based on the respondents' SES. Table 3 reflects the results of the Pearson's correlational analysis.

Pearson's product-moment correlational coefficient, Pearson's $r$, was used to determine if a statistically significant relationship exists between SES and personal perceived responsibility for food access. Based on the applied statistical test, SES and perceived personal responsibility for food access were shown to be statistically significantly correlated. Results indicate that SES accounts for 18.6 percent of the variability in the DV and that there is a positive correlation with a moderate effect size between SES and perceived personal responsibility for food access $(r(24)=0.43, p=0.028)$; where food access is defined as the economic and physical accessibility to sufficient, safe, affordable and nutritious food all year round. Therefore, results of this study identify a statistically significant difference in how individuals perceive personal responsibility for food access based on their SES. 
Table 3 Pearson's Correlation Coefficient

\begin{tabular}{llll}
\hline & & Adjusted Income & \multicolumn{1}{c}{$\begin{array}{l}\text { Perceived } \\
\text { Responsi- } \\
\text { bility }\end{array}$} \\
\hline Adjusted Income & Pearson Correlation & 1 & $0.431^{*}$ \\
& Sig. (2-tailed) & - & 0.028 \\
Perceived Responsibility & $\mathrm{N}$ & 26 & 26 \\
& Pearson Correlation & $0.431^{*}$ & 1 \\
& Sig. (2-tailed) & 0.028 & - \\
& $\mathrm{N}$ & 26 & 26 \\
\hline
\end{tabular}

Source: Author's calculations

$* p<0.05$

\section{Post-hoc Analyses}

Post-hoc analyses were also performed utilizing the independent-samples $t$ test to test differences between the means of those in different SES levels. To perform post-hoc analyses on the self-reported standardized household income data, data was categorized and analyzed within the context of a specific SES class in order to discuss post-hoc results in detail. Therefore, a method of delineation was developed for this study to determine the demarcation between low, middle, and high SES based on adjusted household income levels. To calculate and define thresholds between low, median, and high-income levels, the Pew Research Center designation for determining what constitutes the middle-class was used that identifies middle-class as falling between 67 to 200 percent of the median household income.

The Pew Research Center middle-class percentage range was applied to the ACS median published household income for the city of Danville, KY listed for 2013-2017; $\$ 37,045$ (U.S. Census Bureau 2019). The goal was not only to identify the lower and upper limits of what this study identifies as middle-class (from the city's median household income perspective), but at the same time created a distinct measure of upper and lower thresholds used for classification and post-hoc analysis. Applying the percentages to the median household income of $\$ 37,045$ obtained from the ACS, division between low and middle-class was calculated as $\$ 24,820$ (Rounded-\$24,820.15) and the division between upper and middle-class was calculated as $\$ 74,090$. Thus, the designation used in post-hoc study as a guide when referring to low, middle, and upper-class are as follows: low SES$\$ 0$ to $\$ 24,820$; middle SES - between $\$ 24,820$ and $\$ 74,090$; and high SES-greater than $\$ 74,090$.

Utilizing common equivalency scale calculations, a household of five earning $\$ 50,000$ per year would have an adjusted income of $\$ 22,360$, whereas a household of two making the same amount would have an adjusted income of $\$ 35,355$; the five-person household would be categorized as low SES in this study. It is noted that this procedure to identify the class boundaries adds a qualitative component as, with no specific universal designation to identify or distinguish between social classes, the researchers determined the process, selected the method, and calculated the threshold limits for this study.

Utilizing the demarcations identified for low, middle, and upper SES levels, no cases in this study resulted in a household adjusted income level that met the calculated requirement 
of 200 percent of the median household income identified for Danville, KY. Therefore, with a two-group design the independent-samples $t$ test was used for analysis as the data met the assumptions of independent samples, normality of the dependent variable, and homogeneity of variance based on Levene's test. Three independent-samples $t$ tests were conducted as, in addition to the $\$ 24,820$ demarcation calculated above between low and middle SES, additional cutoff values for additional income levels were also checked as a point of interest. Results of the three post-hoc independent-samples $t$ tests performed are found in Table 4.

Utilizing the $\$ 24,820$ income value demarcation (where low and middle SES groups were separated by the calculated value of $\$ 24,820$ ), those in the low SES group had lower total perceived responsibility scores for food access $(M=15.4, S D=5.03)$ compared to adjusted household income levels identifying the middle-class designation $(M=19.38$, $S D=3.58$ ). An independent-samples $t$ test was computed to compare groups and the difference was found to be significant, $t(24)=-2.07, p=0.049, r^{2}=0.19$. Therefore, those in the lower SES category perceived themselves as having significantly less responsibility than those reflecting the middle class in this study at 95 percent CI [-7.958, -0.01]. In addition, results were also significant when utilizing the demarcation value of $\$ 30,000$ for further comparison of means $\left(t(24)=-2.22, p=0.036, r^{2}=0.19\right)$ as those in the lower SES group had lower total perceived responsibility for food access $(M=16.13, S D=4.26)$ than those in the middle SES group $(M=19.72, S D=3.63)$; 95 percent CI [-6.95, -0.25].

\section{Discussion and Conclusions}

As the world experiences a continued rise in deaths from NCDs, it is simultaneously faced with addressing overconsumption alongside hunger and malnutrition. The topic of food access has gained much global attention regarding potential solutions or pathways to improvement; where food access is defined as the economic and physical accessibility to sufficient, safe, affordable and nutritious food all year round. Unfortunately, global efforts to improve food access and subsequently address related worldwide concerns and issues have failed under the current partnership model that develops close associations and ties with industry. This failed approach, endorsed by the UN in their Sustainable Development

Table 4 Results of Independent-Samples t Test

\begin{tabular}{|c|c|c|c|c|c|c|c|}
\hline \multirow{3}{*}{$\begin{array}{l}\text { Test \# } \\
\\
1\end{array}$} & \multirow{3}{*}{$\begin{array}{l}\text { aBetween } \\
\text { Groups Demar- } \\
\text { cation } \\
\$ 24,820\end{array}$} & \multicolumn{6}{|c|}{$\mathrm{t}$ Test for Equality of Means } \\
\hline & & \multirow{2}{*}{$\begin{array}{l}\mathrm{t} \\
-2.071\end{array}$} & \multirow{2}{*}{$\begin{array}{l}\text { df } \\
24\end{array}$} & \multirow{2}{*}{$\begin{array}{l}\text { Significance } \\
\text { Level } \\
\text { (2-tailed) } \\
0.049^{* *}\end{array}$} & \multirow{2}{*}{$\begin{array}{l}\text { Mean Difference } \\
-3.981\end{array}$} & \multirow{2}{*}{$\begin{array}{l}\text { Standard } \\
\text { Error of Dif- } \\
\text { ference } \\
1.922\end{array}$} & $\begin{array}{l}95 \text { percent } \\
\text { Confidence } \\
\text { Interval }\end{array}$ \\
\hline & & & & & & & $\begin{array}{ll}-7.948 & -0.014\end{array}$ \\
\hline 2 & $\$ 30,000$ & -2.215 & 24 & $0.036^{* *}$ & -3.597 & 1.624 & $-6.949-0.246$ \\
\hline 3 & $\$ 40,000$ & -1.958 & 24 & 0.062 & -3 & 1.532 & -6.1620 .162 \\
\hline
\end{tabular}

Source: Author's calculations

Notes. There were no additional adjusted household income values between $\$ 30,000$ and $\$ 35,000$

a) Delineation between the two groups (low and middle SES)

$* * p<0.05$ 
Goals, continues to be a failed pursuit as they recently admitted that very little progress has been made under the current model in providing access to healthier products.

As such, this research study offers a novel multi-disciplinary approach to a growing global issue by focusing on the individual; a unit of analysis perspective. This perspective was originally suggested by Coleman and Fulford (2020), and this study is an attempt to provide empirical substantiation of this proposed approach. In simplest terms, the approach attempts to understand how the individual perceives themselves in the current food access model as it relates to a level of responsibility; is their view more internal or external in nature? This study hypothesized that the individual would believe themselves to have a higher level of individual responsibility for food access as income levels increased and a relationship would be identified between SES and perceived personal responsibility for food access. Thus, while proposed solutions at the global partnership level attempt to solve issues with broad or top-down approaches unsuccessfully, this study highlights the need to instead begin with the individual and how they perceive the situation. Beginning with the individual is key as any solution that relies on engagement or a shift in individual choices or behaviors must first understand the barriers that the affected individuals themselves see as limiting factors. Only through understanding the individual experience is it offered that tailored solutions be presented that directly relate to the existing barriers and issues experienced from the unit of analysis level.

Results of the main study indicated that there is a statistically significant relationship between one's SES level as determined by income and how the individual perceives personal responsibility for food access; the variables demonstrate a moderate effect size and are positively correlated. Thus, those with higher incomes, standardized based on the number of persons in the household, had higher self-reported total responsibility scores than those with lower incomes. Post-hoc analysis supports the main study as a significant difference in perceived total responsibility scores was found between low and middle SES groups based on scale scores. Findings demonstrate that those with higher adjusted incomes see themselves as having greater responsibility for food access whereas those with lower standardized household incomes viewed themselves as having less responsibility for food access. This result indicates that those of lower SES viewed food access as being beyond their control or the responsibility of others. Thus, those from lower SES levels tend to place responsibility on external parties whereas there appears to be a greater sense of ownership connected with personal actions and behaviors as SES increases.

We offer that one possible explanation for the statistically significant relationship found in this study is the unique application of the social psychological phenomena of learned helplessness (LH). The use of LH to explain different perspectives relating to one's responsibility for food access supports the current disconnect between proposed global solutions, well-intended local movements, current results, and the ultimate desired outcomes. As this study demonstrates, there are differences across SES levels in individual food access beliefs regarding responsibility. Thus, it is no surprise that those who see themselves as having more responsibility in the process will engage in proactive actions and behaviors at a greater rate than those who do not. Additionally, solutions on a broad level that call or rely on the individual to proactively engage through such behavioral changes as making better choices for example, will undoubtedly be more effective with those at greater income levels while the same proposal will, in large part, result in no effective outcome for those who need it the most.

The uniqueness of individual experiences as it relates to LH further contributes to individual behaviors and actions in relation to the notion of whether they experience universal helplessness or personal helplessness. These distinctions further support the linear 
relationship observed in this study as individuals will respond differently to the same stimuli due to the fact that they attribute the idea of control to different things. Thus, broad solutions to the issue of food access are ineffective as they generalize to situations that can be very different from one another and as such, miss the real issues at the point of impact completely; overlooking the individual meant to benefit the most as what works in one area may not work in the next.

This recognition of universal or personal $\mathrm{LH}$ as a conceptual framework also applies to food movements intended to be change agents in response to the ineffective global model as those with universal helplessness believe there is nothing neither they, nor anyone else, can do to change their situation. Those experiencing personal helplessness on the other hand believe that there are actions that impact outcomes, however, they themselves do not believe they can exhibit that response. Therefore movements, even those at a local level, that do not understand the individualized concerns of those most affected will fall short if relying on those whose experiences have resulted in disconnecting actions and outcomes completely through LH (a universal helplessness perspective). These are individuals who may place more trust in, or rely more heavily on, epistemic authority.

\section{Limitations of the Study}

Limitations to the research include the localized sample used in the study. While there is no reason to believe that the City of Danville, KY would be uniquely different from other locations within the U.S., it is still only a representative sample from one city at a particular point in time. In addition, the study was conducted in a city located in the U.S., findings may not be applicable to other countries. Thus, while a statistically significant relationship was determined between SES and perceived personal responsibility for food access, the findings may not be generalizable to the other locations where the context may be different (time, culture, politics, etc.).

While the sample size was deemed appropriate for this research study based on the effect size found in other completed studies between SES and measures of self-efficacy, the small number of participants utilized may be a limitation to greater generalization. There were also no cases where the adjusted household income level fell within the upper-class designation for post-hoc analysis, as most participants were middle class. Therefore, a limitation would be the inability to statistically test the hypothesis incorporating data from the higher SES level. Retirees were also not included in the sample that was further defined as those employed or of pre-retirement age - where birth year was not among the data collected. Thus, the sample parameters may have an impact on the study outcome.

A further limitation is the lack of research regarding SES and a measure of self-efficacy; here, personal perceived responsibility for food access. This does not allow the study to be compared to other studies in different locations consisting of different sizes and contextual influences. This study introduces a unique application and approach to food access and as such, large scale actions resultant of this study should be tempered until additional and confirmatory studies are available to contextualize findings.

In addition, although LH is offered as a possible explanation as to why those of differing SES perceive their responsibility for food access differently, this study did not research this directly and results obtained do not provide details as to why the statistical relationship exists. It is also likely that other variables not identified in this study affect perceived responsibility for food access beyond SES. Therefore, while there is a statistically 
significant relationship between the independent and dependent variables, additional unidentified variables also likely contribute to one's perception of responsibility.

Finally, an existing reliable instrument was modified and utilized in this study resulting in continued high reliability; five scale questions remained for the research study following the pilot study and adjustments. A potential limitation from this may be attributed to the number of questions used in the analysis and the number of factors covered by the instrument relating to responsibility. It is possible that more questions or additional factors on an instrument may provide a wider range of understanding to the relationship.

\section{Implications for Practice}

Results of the study demonstrate that one's adjusted household income level affects how they view themselves in the food access paradigm. Practical solutions or approaches that lead effective change relating to food access need to recognize that not all individuals view food access as a personal responsibility at the same level as others. Thus, proposed solutions that rely on individual engagement or action will not produce equal or desired results as those most in need may ultimately realize the least amount of benefit; through being unable or unwilling. In addressing food access, global actors must take this into account and increase their level of involvement at the point of impact in order to positively affect those who view improved food access as an external responsibility. By focusing on tailored results that directly address the individual differences related to responsibility perspectives across SES levels, it is possible that significant and targeted solutions will not only positively affect individual wellness and quality of life, but will subsequently have a positive effect on global healthcare costs as well as potentially minimizing the perceptions of disconnectedness between actions and behaviors experienced by those of lower SES.

\section{Global and Local Leadership Engagement}

From a leadership perspective and as an approach from local and multinational corporations (MNCs) that includes the global actors concerned and involved by choice, necessity, or association in the discussions and partnerships surrounding the improvement of nutritional food access worldwide, it is worth offering a different lens through which to view the issues. Under the current global model, one could argue that the approach to food access is counter-productive to not only the individuals who are being impacted the most, but to the very organizations themselves who outwardly subscribe to CSR activities and partner in expressed support of SDGs, while stopping short of experiencing monetary inconveniences in addressing a global issue. The current partnerships thus can exhibit the appearance of greenwashing and not reflect genuine interest in refocusing efforts; which is why it is interesting that while part of the problem, industry has been called on to also be part of the solution without a change in focus demonstrated by action from these global partnerships. Thus, it should be recognized that those not interested in solving the problem, never will.

Implications, motivations, and incentives for organizations to adopt this individualized approach in relation to food access also extend further. Refocusing global leadership to engage in a bottom-up approach that simultaneously recognizes that organizations are made up of a collective of individuals, companies may recognize internal value as a secondary benefit to this new perspective on a currently perceived external issue. In other words, leaders should understand that when individuals, who are also the same people who comprise 
the existing and potential workforce, have access to nutritional foods in lieu of those linked to NCDs and obesity, that lower healthcare costs, fewer lost workdays, increased productivity, and increased profit can result.

Therefore, from a practical application standpoint and to support the change process, organizations may find a deeper interest in approaching the issue as focusing on improved worker access to nutritional food seems a more reasonable starting point for those organizations that have been historically viewed as part of the problem. The shift to focusing on improved individual health within each organization through improvement of food access appears a much more palatable and feasible undertaking to affect positive change but requires a shift in mindset and pathway to achieve stated goals. Whether one agrees that businesses are in place solely to make a profit or they have responsibilities for the direct or indirect impacts they have on the environment and social worlds within which they operate, this change of lens allows the leader to be conscious of shareholders and stakeholders while simultaneously impacting both the individual and surroundings. This shift in focus allows leaders to be consistent in working toward the betterment of the company while at the same time, addressing individual needs and concerns of community and employees one step at a time.

It is here that we also find support for the least-cost principles (see Wenar 2007) which, in relation to this study, places the responsibility for action on the actor who is capable and willing to act without excessive burden. This may mean that responsibility is initially placed on those with the greatest resources, such as corporations or governments, and later shifted to individuals. While one can argue that ultimate responsibility lies with the individual, the understanding of LH developed from lived experiences would suggest that external support and action is needed to begin to alter the mindset of those who have disconnected from engaging. In this manner, past experiences of individuals may be able to be shifted from universal to personal helplessness and later to having the confidence and means to personally engage as they learn to associate action with outcomes. From a practical standpoint, this would appear to be in line with Corporate Social Responsibility (CSR) and would therefore not only require a shift in the individual mindset, but a renewed commitment to the individual and issues involved above and beyond profit and market share by corporations. In other words, focus could be shifted to a more relational-based model that can remain profitable while at the same time displaying actions that proactively mitigate the current issue. Restructuring as part of CSR initiatives may mean that ethical considerations are revisited in an effort to reevaluate how the competitive market is approached.

Further, food movements such as food sovereignty and food justice, and even farmer's markets, must also recognize that SES has an effect on participation and the movements may unconsciously be missing a great portion of the community they intend to serve. The explanation of LH offered in this research as a potential reason for the statistically significant relationship between SES and personal perceived responsibility means that individual experiences and how they have previously associated negative outcomes (universal helplessness or personal helplessness) ultimately effects their participation and future actions or inactions, even if the actions will be to their benefit. This means that not only at the global level, but at the local level, the individual should be the focus as even local organizations intended to combat the global paradigm have failed to take hold. With this approach, initial growth and impact may be and appear slow, but a continued focus on the individual means many actors and organizations with a simultaneous focus on the individual, will quickly realize a positive shift at the community and global level; potentially reflected in lower NCD and obesity rates that currently are on the rise in the name of profit and partnerships. 
Author's contributions Both authors contributed to the study. Material preparation, data collection, and analysis were performed by Robert A. Coleman. The first draft of the manuscript was written by Robert A. Coleman and both authors commented on previous versions of the manuscript. Both authors read and approved the final manuscript.

Funding No funding was received for conducting this study.

Availability of data and material Provided with manuscript submission.

Code availability Not applicable.

\section{Declarations}

Conflicts of interest/Competing interest The authors have no relevant financial or non-financial interests to disclose.

Ethics approval This study was performed in line with the principles of the Declaration of Helsinki. Approval was granted by the Internal Review Board of Campbellsville University (July 18, 2019/No. 524).

Consent to participate/publish Informed consent for the use of collected data from was obtained for all anonymous participants included in the study.

\section{References}

Anaf, Julia, Frances E. Baum, Matt Fisher, Elizabeth Harris, and Sharon Friel. 2017. Assessing the Health Impact of Transnational Corporations: A Case Study on McDonald's Australia. Globalization \& Health 13 (7): 1-16. https://doi.org/10.1186/s12992-016-0230-4.

Ashbaugh, Andrea, Laurie A. Gelfand, and Adam S. Radomsky. 2006. Interpersonal Aspects of Responsibility and Obsessive Compulsive Symptoms. Behavioural and Cognitive Psychotherapy 34 (2): 151163. https://doi.org/10.1017/S1352465805002699.

Barber, James G. 1986. The Promise and the Pitfalls of Learned Helplessness Theory for Social Work Practice. The British Journal of Social Work 16 (5): 557-570.

Barrett, Roxanne, Abigail L. Wroe, and Fiona L. Challacombe. 2016. Context Is Everything: An Investigation of Responsibility Beliefs and Interpretations and the Relationship with Obsessive-Compulsive Symptomatology across the Perinatal Period. Behavioural \& Cognitive Psychotherapy 44 (3): 318330. https://doi.org/10.1017/S1352465815000545.

Batsching, Sophie, Reinhard Wolf, and Martin Heisenberg. 2016. Inescapable Stress Changes Walking Behavior in Flies - Learned Helplessness Revisited. PLoS ONE 11 (11): 1-16. https://doi.org/10.1371/ journal.pone.0167066.

Blay-Palmer, A., Roberta Sonnino, and Julien Custot. 2016. A Food Politics of the Possible? Growing Sustainable Food Systems Through Networks of Knowledge. Agriculture and Human Values 33 (1): $27-43$.

Botterill, Jacqueline. 2017. Mobile Eating: A Cultural Perspective. International Review of Social Research 7 (2): 71-79. https://doi.org/10.1515/irsr-2017-0009.

Browning, Peter. 2017. The global Obesity Epidemic: Shifting the Focus from Individuals to the Food Industry. Journal of the Society of Christian Ethics 37 (1): 161-178.

Calveras, Aleix, and J. Juan-José Ganuza. 2016. The Role of Public Information in Corporate Social Responsibility. Journal of Economics \& Management Strategy 25 (4): 990-1017. https://doi.org/10. $1111 /$ jems.12156.

Canfield, Matthew, Molly D. Anderson, and Philip McMichael. 2021. UN Food Systems Summit 2021: Dismantling Democracy and Resetting Corporate Control of Food Systems. Front. Sustain. Food Syst. 5: 661552. https://doi.org/10.3389/fsufs.2021.661552.

Chan, Kai M. A., John Agard, Jianguo Liu, Ana Paula D. de Aguir, Dolors Armenteras, Agni Klintuni Boedhihartono, William W. L. Cheung, et al. 2019. Chapter 5. Pathways towards a sustainable future. Global assessment report of the intergovernmental science-policy platform on biodiversity and 
ecosystem services, eds. Brondízio, E. S., Settele, J., Díaz, S., Ngo, H. T., 108. Bonn: IPBES secretariat. https://doi.org/10.5281/zenodo.3832099

Chen, Susan, and Le. Wang. 2021. SNAP participation, diet quality, and obesity: Robust evidence with estimation techniques without external instrumental variables. Empirical Economics 61 (3): 16411667. https://doi.org/10.1007/s00181-020-01902-7.

Chen, You-Hua., Xiao-Wai. Wen, and Ming-Zhong. Luo. 2016. Corporate Social Responsibility Spillover and Competition Effects on the Food Industry. Australian Economic Papers 55 (1): 1-13. https://doi.org/10.1111/1467-8454.12058.

Civil Society and Indigenous Peoples' Mechanism: For Relations with the UN Committee on World Food Security. 2021. "What's Wrong With the United Nations Food Systems Summit in CSM's View." Retrieved from: https://www.csm4cfs.org/14024-2/

Clendenning, Jessica, Wolfram Dressler, and Carol Richards. 2016. Food Justice or Food Sovereignty? Understanding the Rise of Urban Food Movements in the USA. Agriculture \& Human Values 33 (1): 165-177. https://doi.org/10.1007/s10460-015-9625-8.

Coleman, Robert A. and Mark D. Fulford. 2020. "Ready, Fire, Aim: The Underperformance of Current Food Access Efforts and "Food for Thought" Regarding Potential Solutions." Food Ethics 5(10). https://doi.org/10.1007/s41055-020-00070-9.

Cornil, Yann, Pierrick Gomez, and Dimitri Vasiljevic. 2020. Food as Fuel: Performance Goals Increase the Consumption of High-Calorie Foods at the Expense of Good Nutrition. Journal of Consumer Research 47 (2): 147-166. https://doi.org/10.1093/jcr/ucaa012.

Daivadanam, Meena, K.R. Rolf Wahlström, and Thankappan, and T. K. Sundari Ravindran. . 2015. Balancing Expectations Amidst Limitations: The Dynamics of Food Decision-Making in Rural Kerala. BMC Public Health 15 (1): 1-13. https://doi.org/10.1186/s12889-015-1880-5.

Darin-Mattsson, Alexander, Stefan Fors, and Ingemar Kåreholt. 2017. Different Indicators of Socioeconomic Status and Their Relative Importance as Determinants of Health in Old Age. International Journal for Equity in Health 16 (1): 1-11. https://doi.org/10.1186/s12939-017-0670-3.

Ebert, Udo, and Patrice Moyes. 2003. Equivalence Scales Reconsidered. Econometrica 71 (1): 319-343. https://doi.org/10.1111/1468-0262.00397.

FAO, IFAD, UNICEF, WFP and WHO. 2021.The State of Food Security and Nutrition in the World 2021. Transforming food systems for food security, improved nutrition and affordable healthy diets for all. Rome, FAO.https://doi.org/10.4060/cb4474en

Fincham, Frank D., Audrey Hokoda, and Jr. Reliford Sanders. . 1989. Learned Helplessness, Test Anxiety, and Academic Achievement: A Longitudinal Analysis. Child Development 60 (1): 138-145. https://doi.org/10.2307/1131079.

Garner, Thesia I., Javier Ruiz-Castillo, and Mercedes Sastre. 2003. The Influence of Demographics and Household-Specific Price Indices on Consumption-Based Inequality and Welfare: A Comparison of Spain and the United States. Southern Economic Journal 70 (1): 22-48. https://doi.org/10.2307/ 1061630 .

Gostin, Lawrence O. 2016. "Big Food” Is Making America Sick. Milbank Quarterly 94 (3): $480-484$. https://doi.org/10.1111/1468-0009.12209.

Guo, Yimeng, Jacek A. Kopec, Jolanda Cibere, Linda C. Li, and Charles H. Goldsmith. 2016. Population Survey Features and Response Rates: A Randomized Experiment. American Journal of Public Health 106 (8): 1422-1426. https://doi.org/10.2105/AJPH.2016.303198.

Havranek, Michael M., Bianca Bolliger, Sophie Roos, Christopher R. Pryce, Boris B. Quednow, and Erich Seifritz. 2016. "Uncontrollable and Unpredictable Stress Interacts with Subclinical Depression and Anxiety Scores in Determining Anxiety Response". Stress: The International Journal on the Biology of Stress 19(1): 53-62. https://doi.org/10.3109/10253890.2015.1117449.

HLPE. 2021. Promoting youth engagement and employment in agriculture and food systems. A report by the High Level Panel of Experts on Food Security and Nutrition of the Committee on World Food Security, Rome.

Holt-Giménez, Eric, and Raj Patel. 2009. Food Rebellions! Crisis and the Hunger for Justice. Oxford: Pambazuka Press.

Jones, Andrew D., and Gebisa Ejeta. 2016. A New Global Agenda for Nutrition and Health: The Importance of Agriculture and Food Systems. Bulletin of the World Health Organization 94 (3): 228-229. https://doi.org/10.2471/BLT.15.164509.

Kemmelmeier, Markus. 2016. Cultural Differences in Survey Responding: Issues and Insights in the Study of Response Biases. International Journal of Psychology 51 (6): 439-444. https://doi.org/10. 1002/ijop.12386. 
Kobori, O., Paul M. Salkovskis, Rowena Pagdin, Julie Read, and Brynjar Halldorsson. 2017. Carer's Perception of and Reaction to Reassurance Seeking in Obsessive Compulsive Disorder. Cognitive Behaviour Therapist 10: 1-17. https://doi.org/10.1017/S1754470X17000095.

Leary, R. Bret., and Garret Ridinger. 2020. Without Determination: The Impact of Systemic Market Access Denial on Consumer Power and Market Engagement. Journal of Public Policy \& Marketing 39 (2): 99-118. https://doi.org/10.1177/0743915619885393.

Li, Hongxia, and Guoquan Chen. 2018. Benevolence-Dependability Value and Intertemporal Choice: Moderating Effect of Perceived Socioeconomic Status. Social Behavior \& Personality: An International Journal 46 (9): 1573-1583.

Lozano-Cabedo, Carmen, and Cristóbal Gómez-Benito. 2017. A Theoretical Model of Food Citizenship for the Analysis of Social Praxis. Journal of Agricultural \& Environmental Ethics 30 (1): 1-22. https://doi.org/10.1007/s10806-016-9649-0.

Manoussaki, Kallia. 2015. Responsibility Attitude and Stimulus Valence in Relation to Recognition and Confidence in Recognition of Words. Psychology 6 (9): 1159-1167.

Marks, Jonathan H. 2017. Caveat Partner: Sharing Responsibility for Health with the Food Industry. American Journal of Public Health 107 (3): 360-361. https://doi.org/10.2105/AJPH.2016.303646.

Mialon, Melissa, Boyd Swinburn, Steven Allender, and Gary Sacks. 2016a. Systematic Examination of Publicly-Available Information Reveals the Diverse and Extensive Corporate Political Activity of the Food Industry in Australia. BMC Public Health 16 (1): 1-13. https://doi.org/10.1186/ s12889-016-2955-7.

Mialon, Melissa, Boyd Swinburn, Jillian Wate, Isimeli Tukana, and Gary Sacks. 2016b. Analysis of the Corporate Political Activity of Major Food Industry Actors in Fiji. Globalization \& Health 12 (May): 1-14. https://doi.org/10.1186/s12992-016-0158-8.

Niu, Lian. 2017. Family Socioeconomic Status and Choice of Stem Major in College: An Analysis of a National Sample. College Student Journal 51 (2): 298-312.

Persoskie, Alexander, Erin Hennessy, and Wendy L. Nelson. 2017. "US Consumers' Understanding of Nutrition Labels in 2013: The Importance of Health Literacy." PREVENTING CHRONIC DISEASE 14(September). https://doi.org/10.5888/pcd14.170066.

Popkin, Barry M., Linda S. Adair, and Shu Wen Ng. 2012. Global Nutrition Transition and the Pandemic of Obesity in Developing Countries. Nutrition Reviews 70 (1): 3-21. https://doi.org/10.1111/j. 1753-4887.2011.00456.x.

Psaki, Stephanie R., Jessica C. Seidman, Mark Miller, Michael Gottlieb, Zulfiqar A. Bhutta, Tahmeed Ahmed, A. M. Shamsir Ahmed, et al. 2014. "Measuring Socioeconomic Status in Multicountry Studies: Results from the Eight-Country MAL-ED Study." Population Health Metrics 12(March). doi:https://doi.org/10.1186/1478-7954-12-8.

Reznik, Samantha, Robin Nusslock, Narun Pornpattananangkul, Lyn Y. Abramson, James Coan, and Eddie Harmon-Jones. 2017. Laboratory-Induced Learned Helplessness Attenuates Approach Motivation as Indexed by Posterior versus Frontal Theta Activity. Cognitive, Affective \& Behavioral Neuroscience 17 (4): 904-916. https://doi.org/10.3758/s13415-017-0521-0.

Salkovskis, P.M., A.L. Wroe, A. Gledhill, N. Morrison, E. Forrester, C. Richards, M. Reynolds, and S. Thorpe. 2000. Responsibility Attitudes and Interpretations Are Characteristic of Obsessive Compulsive Disorder. Behaviour Research and Therapy 38 (4): 347-372.

Scott, Lara. 2017. Food Choice Behaviour: Why Clients Are Unable to Easily Change Their Eating Habits. Journal of the Australian Traditional-Medicine Society 23 (3): 136-139.

Sorrenti, Luana, Pina Filippello, Sebastiano Costa, and Caterina Buzzai. 2015. A Psychometric Examination of the Learned Helplessness Questionnaire in a Sample of Italian School Students. Psychology in the Schools 52 (9): 923-941. https://doi.org/10.1002/pits.21867.

Stuckler, David, and Marion Nestle. 2012. Big Food, Food Systems, and Global Health. PLoS Medicine 9 (6): 1-4. https://doi.org/10.1371/journal.pmed.1001242.

Tempels, Tjidde, Marcel Verweij, and Vincent Blok. 2017. Big Food's Ambivalence: Seeking Profit and Responsibility for Health. American Journal of Public Health 107 (3): 402-406.

U.S. Census Bureau. 2019. Income in the Past 12 Months (In 2017 Inflation-Adjusted Dollars). 20132017 American Community Survey 5-year Estimates - Table DP03 [Database record]. Retrieved from http://factfinder.census.gov.

United Nations Economic and Social Council. Committee on Economic, Social and Cultural Rights (CESCR), General Comment No. 12: The Right to Adequate Food (Art. 11), para. 6, U.N. Doc. E/C.12/1999/5 (1999, May 12).

United Nations General Assembly, International Covenant on Economic, Social and Cultural Rights, International Covenant on Civil and Political Rights and Optional Protocol to the International Covenant on Civil and Political Rights. (1966, December 16). A/RES/2200. 
United Nations General Assembly, Transforming Our World: the 2030 Agenda for Sustainable Development. (2015, October 21). A/RES/70/1.

Urbaniak, Geoffrey C., and Scott Plous. 2013. Research Randomizer (Version 4.0).

Usher, Kareem M. 2015. Valuing All Knowledges through an Expanded Definition of Access. Journal of Agriculture, Food Systems \& Community Development 5 (4): 1-6. https://doi.org/10.5304/jafscd.2015. 054.018.

Wang, Qing, Jay J. Shen, Michelle Sotero, Casey A. Li, and Zhiyuan Hou. 2018. Income, Occupation and Education: Are They Related to Smoking Behaviors in China? PLoS ONE 13 (2): 1-17. https://doi.org/ 10.1371/journal.pone.0192571.

Wenar, Leif. 2007. Responsibility and Severe Poverty. In Freedom from Poverty as a Human Right, ed. T. Pogge, 255-274. Oxford: Oxford University Press.

Wiist, William H. 2017. Contraindications and Alternatives to Nuanced Corporate Responsibility. American Journal of Public Health 107 (6): e5-e6. https://doi.org/10.2105/AJPH.2017.303774.

Wittman, Hannah. 2011. Food Sovereignty: A New Rights Framework for Food and Nature? Environment \& Society Environment \& Society 2 (1): 87-105. https://doi.org/10.3167/ares.2011.020106.

World Health Organization. 2021. Obesity and Overweight. Retrieved from https://www.who.int/newsroom/fact-sheets/detail/obesity-and-overweight.

Publisher's Note Springer Nature remains neutral with regard to jurisdictional claims in published maps and institutional affiliations. 